\title{
PROOF
}

\section{1 \\ How to Gauge Moral Intuitions? Prospects for a New Methodology}

Martin Bruder and Attila Tanyi

\subsection{The role and significance of intuitions}

The concept of moral intuitions reflects the idea that there are moral truths and that people arrive at these truths not primarily by a process of reflection and reasoning but rather by a more immediate process somewhat akin to perception. ${ }^{1}$ This is crucial from a philosophical point of view: Intuitions matter for a philosopher because they are taken to have evidential value. Alvin Goldman's (2007, p. 2, italics in original) remark on Gettier's challenge to the account of knowledge as justified true belief well illustrates the point:

It wasn't the mere publication of Gettier's two examples, or what he said about them. It was the fact that almost everybody who read Gettier's examples shared the intuition that these were not instances of knowing. Had their intuitions been different, there would have been no discovery.

Although Goldman's remark is about epistemology, moral theory appears to be no different when it comes to the relevance and significance of moral intuitions. Like observations in science, intuitions are the raw data that competing moral theories should at least try to accommodate: If an intuition counts in favor of a theory, this is good for the theory; if an intuition counts against a theory, this is bad for the theory. All this goes only prima facie, of course. There can be grounds to discount intuitions, or even not to take them into consideration; and there can be other mental states - hunches, premonitions, gut feelings, guesses - that may appear at first to be intuitions but are not. It is also possible that, on balance and compared to other theories, a moral theory turns out to 


\section{PROOF}

be the best available even though it has counterintuitive implications. Nevertheless, intuitions have initial credibility for (most) philosophers; this is why intuitions have always been important in philosophy.

More recently, the investigation of intuitions has also moved into focus of research in moral psychology, a field that arguably is importantly relevant for experimental moral philosophy. But in contrast to moral philosophy, moral psychology had long neglected moral intuitions. During most of the 20th century, psychologists' treatment of morality has focused on the development of reflective and consciously accessible moral reasoning capacities in children. In particular, Jean Piaget (1999/1932) and Lawrence Kohlberg (1984) have introduced influential stage models of moral-cognitive development. However, in the course of the so-called 'affective revolution' and under the influence of a new focus on non-conscious processes, the last 25 years have seen a revival of the role of intuitions in theorizing in moral psychology (Haidt and Kesebir, 2010).

Although moral intuitions therefore have met with strong and growing interest in both philosophy and psychology, in philosophy at least, there is a range of opposing voices questioning whether this interest is justified. One can be skeptical about the supposed generality of intuitions, both concerning their content (whether they are about specific cases or general principles as well; see, e.g., Hintikka, 1999) and also concerning the scope of their holders (whether they are held by everyone or nearly everyone; see, e.g., Appiah, 2008; Banerjee, Huebner, and Hauser, 2011). There is also the separate but connected debate about whose intuitions count: everyone's, only the experts', or any idiosyncratic intuition could qualify as evidence (Alexander and Weinberg, 2007; Ryberg, 2013). Finally, there is a significant literature discussing whether intuitions can have an evidential role in the first place (Sosa, 2006; Hales, 2000; Singer, 2005).

In this paper, however, our aim is a different one. We are concerned with two problems that, although related to the concerns mentioned above, are more directly relevant for conducting experimental research in philosophy. The first concerns the question of what intuitions are; the problem being that in the absence of a proper characterization intuitions appear to be strange, a priori, Platonic entities that philosophers, especially those with naturalistic inclinations, have trouble accepting (Goldman, 2007; Hales, 2000; Hintikka, 1999). The second objection to using intuitions as evidence is more epistemological. The idea is that given what intuitions are (that is, given an answer to the first problem), there are insurmountable problems concerning their empirical investigation. 


\section{PROOF}

How to Gauge Moral Intuitions? Prospects for a New Methodology

In other words, the challenge is how to find intuitions, even if we know what they are (Kauppinen, 2007; Podsakoff et al., 2003; Nagel, 2012).

In what follows, we will propose responses to both challenges. In the next Section 11.2, we will put forward an account of intuitions that singles out three essential characteristics for a mental state to count as an intuition: immediacy, lack of inferential relations to other mental states, and stability. ${ }^{2}$ Building on this account, the same section will outline the basics of a new methodology for experimental philosophy. Next, in Section 11.3, we sketch possible studies implementing the proposed methodology. The context will be a particular objection to consequentialism: the so-called overdemandingness objection. Since these studies have not yet been carried out, in Section 11.4 we present the results of a completed experiment attempting to implement some new methodological features. Section 11.5 summarizes the discussion and concludes.

\subsection{The new methodology}

A possible definition of moral intuitions reflecting their evidential, perception-like role is the following: ${ }^{3}$

When we refer to moral intuitions, we mean strong, stable, immediate moral beliefs. These moral beliefs are strong insofar as they are held with confidence and resist counter-evidence (although strong enough counter-evidence can sometimes overturn them). They are stable in that they are not just temporary whims but last a long time (although there will be times when a person who has a moral intuition does not focus attention on it). They are immediate because they do not arise from any process that goes through intermediate steps of conscious reasoning (although the believer is conscious of the resulting moral belief). (Sinnott-Armstrong, Young, and Cushman, 2010, p. 247, italics in original)

In what follows we will take on board the above proposal as giving us two characteristics of intuitions: immediacy and stability (which, in our account, also includes what is called 'strength' above). The social psychologist Jonathan Haidt further elaborates on the first characteristic - immediacy - by stating that 'intuition occurs quickly, effortlessly, and automatically, such that the outcome but not the process is accessible to consciousness' (2001, p. 818). The immediacy of intuitions, however, is only important for philosophers insofar as it increases the likelihood of them being non-inferential: The moral judgments upon which they are 


\section{Martin Bruder and Attila Tanyi}

based are not accepted on the ground that they follow from some moral theory or principle that the agent subscribes to (Tersman, 2008). This is essential if they are to function as evidence that can, at least prima facie, resolve conflict among competing moral theories: they could not support or count against a moral theory were they only to be inferred from that or any other theory. Strangely, this characteristic of intuitions is not mentioned in the above quote, and hence it constitutes an additional aspect in our account. Besides immediacy and lack of inference, philosophers (often in contrast to psychologists) emphasize stability as a further critical characteristic of intuitions. This is because it is difficult to see how intuitions should have evidential value if they were not stable over time. Thus, this condition matters because it helps to elevate intuitions to the level of considered judgments, or, as they were recently called, robust intuitions (as opposed to immediate surface intuitions) (Kauppinen, 2007). Robust intuitions are those immediate of the agent that have, so to speak, withstood the test of reflection: They are those immediate reactions that a competent speaker would retain under sufficiently ideal conditions, such as when the speaker is not biased (Sidgwick, 1907; Liao, 2008). As mentioned, we take this third characteristic to cover both what is called strength and what is called stability in the quotation we began with. That intuitions withstand the test of reflection we take to be the same as the requirement that intuitions 'are held with confidence and resist counter-evidence'. And we also regard intuitions that withstand the test of reflection to be lasting opinions of the agent and not mere temporary whims.

This is, then, our answer to the first question: what are intuitions? Once this account of intuitions is at hand, the next step is to find empirical methods to examine the three core characteristics of intuitions that we have outlined. This will answer the second question of how to find intuitions. The first proposed characteristic poses the least challenge, perhaps. The immediacy of intuitions is a central focus of psychological research on intuitive processes (Glöckner and Witteman, 2010). Much of this research is based on dual-process models of reasoning and social behavior (e.g., Epstein et al., 1996; Evans, 2008). These models propose a distinction between rational, controlled processes (which, in line with Epstein et al., 1996, we will call 'analytical-rational'), on the one hand, and automatic, associative, affect-based processes (which we will call 'intuitive-experiential'), on the other. Intuitive-experiential processes are supposed to operate quickly and with low levels of mental effort and conscious awareness. They therefore capture the immediacy characteristic of intuitions. Standard experimental paradigms are available to test 
the role of intuitive-experiential processes in judgment and decisionmaking. These include, in particular, placing participants under severe time constraints (Horstmann, Hausmann, and Ryf, 2010) or adding cognitive load (i.e., a second task that has to be completed in parallel to the focal task; Gilbert and Hixon, 1991). Both methods rely on inhibiting analytical-rational processes. The underlying rationale is that once conscious reasoning is precluded from operating, what remains are intuitive-experiential processes that generate immediate intuitions concerning the object of the judgment.

In terms of experimental methodology, the supposed non-inferential character of intuitions is particularly challenging. Although immediacy of reaction in the course of an associative, effortless, and non-conscious (i.e., intuitive-experiential) process renders it unlikely that complex inferences made on the basis of a moral theory occur, the speed of a reaction may not by itself be sufficient to demonstrate the lack of inference. We therefore propose a complementary method to address this challenge.

In recent years cognitive theories of emotion have become influential in the philosophy of emotion. In a related development, cognitive appraisal theories of emotion have become the dominant family of theories in psychological emotion research (Moors, 2009). Both families of theories claim that emotions are mental states that have affective, conative, and cognitive aspects at the same time: they are motivating affective states that involve evaluative representations of their objects (Solomon, 1993; Goldie, 2007; Slaby, Stephan, and Walter, 2011). For us it is this latter characteristic that is most important. There are two main interpretations. The more robustly cognitive line has it that the representational intentional content of an emotion is that of a belief or judgment, and the phenomenal - which is also the motivating - aspect is merely added on, without explanation, and without any attempt at synthesis with the emotion's cognitive aspect (e.g., Solomon, 1993). The other, less robustly cognitive, line has it that emotions purport to be perceptions of properties such as being funny, shameful, pitiable, enviable, and so forth: their intentional (representational) content is understood by analogy to sense perception. In this way, since perception, arguably, possesses phenomenology, the intentional (representational) and the affective - thus also the motivational - aspects of emotion are not unrelated, as on the first reading; on the contrary, the former is part of the latter. Emotions are, as Sabine Döring calls them, affective perceptions: they involve a distinct cognition that is distinct exactly because of its phenomenology (Döring, 2003, 2007; Cf. de Sousa, 1987; Roberts, 


\section{Martin Bruder and Attila Tanyi}

1988). This thought gives rise to several important ideas that are directly relevant for the proposed methodology.

First, if emotions are indeed states akin to perceptions, they can be correct and incorrect, depending on how well they track the properties of which they are purportedly representations. It is in this sense that philosophers, as well as non-philosophers, speak of the fittingness of emotions: whether it makes sense to feel an emotion in the given situation. In other words, something like a rationalism of emotions is true (de Sousa, 1987; Peacocke, 1992). Second, if emotions are analogous to perceptions, then this suggests that, like sense perceptions, their content is not inferentially related to the contents of other states. That is, it is possible for an agent to have an emotion the content of which conflicts with the content of the agent's judgment (belief), without any contradiction being involved. There are thus no inferential constraints on emotions, just as there are none on sense perceptions (Döring, 2003). Third, the non-inferential character of emotions opens up the possibility that 'the occurrence of an emotion can, in suitable circumstances, entitle a thinker to judge, and possibly to know, its content simply by taking its representational content at face value. In the case of moral emotions, the possibility emerges that those emotions may give the thinker a non-inferential way of coming to know moral propositions' (Döring, 2003, p. 229). In fact, going one step further, it could be argued that the content of emotions is gestalt-like: coming to know, via the emotion, a moral proposition is like suddenly coming to see how the dots together form Marilyn Monroe's face in a pointillist painting. There are no inferential relations between seeing the dots (morally salient features of the situation), and seeing Monroe's face (moral proposition; cf. Döring, 2003; Little, 1997; Roeser, 2011; Hookway, 2002). Finally, depending on one's views of moral properties, emotions can either be facilitative or constitutive of the process of gaining moral knowledge: in the former case one can, in principle, get to know the moral proposition without the requisite emotion, in the latter case one cannot (cf. D'Arms and Jacobson, 2000).

These ideas are relevant for the new methodology because they suggest that there might be an intimate connection between intuitions and emotions; in fact, some have gone as far as to claim that intuitions are emotions: that something like an affectual intuitionism is true (Roeser, 2011). Assuming for now that an intimate connection (of some sort) exists, it seems that we can begin to address the difficulties surrounding the empirical testability of the non-inferential character of intuitions by focusing on participants' emotional responses to the situation. Insofar 
as these responses are in line with participants' judgments in the situation, we may conclude that those judgments are indeed intuitive. Were it to turn out that there is no correspondence between participants' emotional responses and their moral judgments, we could conclude that participants' judgments are not intuitions. This could happen, we might further hypothesize, because the participant did not endorse, upon reflection, her original immediate judgment. Checking this hypothesis would then take us to the investigation of the third proposed characteristic of intuition, namely, their stability.

Before this happens, however, some further specification of the proposed method to test the non-inferential aspect of intuitions is needed. In particular, endorsing the link between intuitions and emotions requires that experimental at this point focus on testing with which emotions, and how intensively, participants react to experimental situations. This puts a constraint on the new methodology insofar as, of course, it requires that we have better knowledge of and better ways to assess the emotions that correspond to the relevant judgments than knowledge of and ways to assess the intuitions directly. This seems to be the case though, as we can focus on assessing a number of moral emotions, the connections of which to moral properties and judgments are well documented. ${ }^{4}$ Although, in philosophy, moral emotions are typically related to so-called 'thick' properties, such as being pitiable, enviable, etc., some argue for a strong, even constitutive connection between the 'thin' property of wrongness and a moral emotion. Thus, for instance, Allan Gibbard (1990, p. 42) holds that '[w] hat a person does is morally wrong if and only if it is rational for him to feel guilty for doing it, and for others to resent him.' And John Skorupski (2010) analyzes wrongness in terms of blameworthiness, that is, whether it makes sense to feel blame toward a person. (Neuro-)psychological research supports this reasoning. Greene et al. (2001) have shown that there are systematic variations in the engagement of emotion-related brain areas in moral judgments. One emotion that has received substantial empirical attention in moral psychology is disgust. Schnall et al. (2008) demonstrated that disgust can render moral judgments more severe. Focusing on moral emotions may therefore help us, in the way proposed above, to investigate people's moral intuitions concerning wrongness and rightness in the experimental situations.

Lastly, let us turn to the investigation of the stability of intuitions. Similar to research addressing the immediacy of moral intuitions, studies examining their stability will also attempt to elicit spontaneous moral judgments. However, in a second step, these studies will engage 
conscious, analytical-rational mental processes to further examine whether the spontaneous judgments stand the 'test of reflection' and therefore acquire the status of considered judgments.

We believe that the methodological approach proposed here to assessing intuitions positively transcends the strong reliance of research in experimental moral philosophy on unquestioned self-reports of moral judgments. Huebner (2011) has recently argued that such experiments alone cannot establish the intuitive nature of moral judgments. Although no single empirical study that we propose would achieve this goal either (and it can be doubted whether such a study is even a possibility), we believe that our multi-method approach will increase understanding of the intuitive processes involved in making moral judgments. Specifically, the proposed methodology involves investigating whether results are consistent across the different proposed characteristics of moral intuitions. Both stabilities and possible instabilities would be informative in understanding what moral intuitions can and cannot tell us about moral truths.

\subsection{Implementing the new methodology: a project design}

The previous section sketched our proposal for a new methodology. But while more work on the theoretical background of the new methodology is undoubtedly needed, what would even be more useful at this point is to see how the different methods and ideas proposed above would be implemented in practice. In the remainder of the paper, we will therefore present two instances of implementation. Both concern a particular problematic - the so-called overdemandingness objection to consequentialism - and both connect to our previous work on the subject. The first, to be discussed in the present section, outlines our plans for the experimental investigation of the objection by using the entire proposed methodology. The second, to be presented in the next section, presents the results of a study that was already carried out which tested some of our methodological proposals.

Let us begin with the philosophical problematic. Proponents of act-consequentialism hold that the right course of action is the one that produces the best results as judged from an impartial perspective. However, it is often claimed that this requirement is so demanding that it is intuitively unacceptable for anyone to follow it (Hooker, 2009, p. 162 , footnote 4 ; Carter, 2009 , pp. 163-185). This is because, to take 
one example, it would require foregoing most, if not all, non-moral personal projects and devoting one's life almost exclusively to alleviating the suffering of those in need. The so-called Overdemandingness Objection (OD) attempts to use this supposedly common intuition concerning the inadmissibility of extreme demands as a starting point for rejecting consequentialism. Unlike other discussions of the Objection, in our previous work we aimed to test whether the proposed intuition indeed exists (Bruder and Tanyi, 2014 and forthcoming). We examined what we consider to be the strongest version of the Objection, which is based on the presumed inescapability of consequentialist reasons. According to this reading, consequentialism requires the agent with decisive force to do things that, intuitively, she has not decisive reasons to do. ${ }^{5}$

To test whether people indeed have this intuition, we conducted two studies: one survey study that used imaginary decision scenarios, and one experimental game developed in behavioral economics that allowed us to assess the relevant intuition in a decision situation with real consequences. Based on the philosophical literature discussing the Objection, we initially expected that (a) Hypothesis 1: increasing demands would be associated with higher levels of rejection of the consequentialist course of action and (b) Hypothesis 2: that at least in some cases the consequentialist course of action would be perceived as overly demanding by most if not all participants. Surprisingly, we found that, while Hypotheses 1 was indeed confirmed, Hypothesis 2 was not confirmed, thus casting doubt on the plausibility of the Overdemandingness Objection or, at least, on the philosophical relevance of situations that indeed call forth the intuition.

These studies were, however, in many ways constrained, not least in the methods they used to detect intuitions. Hence it appears sensible to see how the proposed new methodology could be implemented to test the two hypotheses above. In what follows we will give a brief outline of three closely related empirical studies (Studies 1-3), each of which focusing on one of the aforementioned characteristics of intuitions. These studies have not yet been carried out, but serve as illustration as to how the proposed methodology may be applied to the Overdemandingness Objection as well as other challenging problems.

Study 1 builds on our previous work and tests whether the intuition underlying OD is immediate. To this end, the study examines whether moral intuitions are stable across processing modes within a given individual. Participants will respond to scenarios similar to those 


\section{Martin Bruder and Attila Tanyi}

used in our previous work. ${ }^{6}$ Before they do so, the study will manipulate the degree to which individuals engage in analytical-rational versus intuitive-experiential processing and examine the effects of this manipulation on moral judgments. The underlying assumption is that participants will engage in analytical-rational processing if they have (a) time and (b) cognitive capacity to do so. Using methods borrowed from social-cognitive psychology, two independent manipulations will attempt to put constraints on both of these factors, thereby increasing participants' reliance on more highly automatized (and thus quicker) intuitive-experiential processes. This is done (a) by limiting the time participants have to respond to the scenarios and (b) by asking them to perform a second task (i.e., memorizing numbers) in parallel to their moral judgment task. Although such manipulations are common in psychological decision-making research, applications to the moral judgment domain are rare. ${ }^{7}$ Thus, this study will provide evidence as to whether the pattern of results observed in our previous work occurs in an immediate and relatively effortless manner. If it does, this will support the idea that those judgments were made on the basis of intuitions.

Study 2 will draw on cognitive theories of emotion to provide some insight into whether the intuition underlying OD is non-inferential. It will employ a novel unobtrusive test targeting the nonverbal behavior associated with moral emotions. Emotions marking individual moral transgressions - such as shame and some forms of embarrassment are reliably related to (a) decreased body expansion, (b) averted gaze, and (c) downward head tilt (e.g., Tracy and Matsumoto, 2008). The study will make use of the novel tool of automated face and posture video analysis to assess the degree to which participants experience such emotions while making moral decisions. This assessment largely avoids response biases that may influence self-reports of emotion while retaining the ability to make inferences concerning relatively specific emotions (which is often not possible with physiological measures of emotions). Because emotions in response to fictitious scenarios may differ from emotions experienced in real decision situations (Parkinson and Manstead, 1993), the study is designed to investigate whether the intuition underlying OD can be observed in the emotions experienced in decisions with real-world consequences. Evidently, these decisions cannot involve equally serious implications as those described in the scenarios. However, economic games provide an established framework to investigate decision making with real monetary outcomes. Although 


\section{PROOF}

How to Gauge Moral Intuitions? Prospects for a New Methodology

167

rarely the case, some studies have used such games to explicitly investigate moral decision-making (e.g., Aguiar, Branas-Garza, and Miller, 2008). Building on a design used in our previous work, participants will distribute an amount of money between themselves and a charitable organization that alleviates suffering in the developing world (e.g., UNICEF). As our independent variable, we will manipulate demand levels by either having participants first 'earn' the money that they later distribute or giving it to them with no effort from their side involved (as a so-called 'windfall endowment'; Cherry, Frykblom, and Shogren, 2002). We will observe both participants' explicit moral judgments and their nonverbal emotional behavior. If expressed emotions were strong indicators of the intuition underlying OD - ideally fully mediating the effect of our manipulation on moral judgments - this would lend increased credibility to the idea that this intuition is indeed non-inferential. As a follow-up study, a more direct test of the role of emotions in generating intuitions would be to experimentally dampen the emotional experience. Seminal work by Strack, Martin, and Stepper (1988) demonstrated that this can be achieved by inhibiting expressive behavior. Thus, if people donated more money when they are able to freely express their emotions than when they are constrained in their expressive behavior (e.g., because they need to stand upright disallowing them to decrease their body expansion congruent with shame), this would be a further indication that the experience of relevant emotions is part of or, at least, a necessary precondition of having the respective moral intuition.

Study 3 will address whether the moral intuition underlying OD is stable. To do so, the study will use an adapted think-aloud procedure to identify participants' reasoning processes while they are making moral judgments (Van Someren, Barnard, and Sandberg, 1994). Participants will be trained to continuously verbalize their thoughts while responding to morally challenging scenarios similar to those used in the pilot work. We will also manipulate whether or not participants are encouraged to reflect in detail on their immediate responses. Thus, some participants will be led to subject their initial responses to a thorough 'test of reflection'. The study therefore focuses on robust intuitions or considered judgments and examines whether the opinion postulated by OD, if found, belongs to this group. If it does, then this would suggest that participants' immediate responses were not only surface intuitions but qualify as robust intuitions, that is, intuitions proper on our account. 


\section{PROOF}

\subsection{Implementing the new methodology: a case study}

As mentioned above, in our previous work we have carried out a scenario study in which participants were asked to make a choice in ethically demanding situations. The sample of this study was representative of the German population in several key characteristics such as age, gender, and education. In one scenario, participants were, for example, asked to imagine that they had a choice between starting work as a civil engineer building an orphanage in Africa (the consequentialist choice option) or taking up a position in their own country (the non-consequentialist choice option). Given the specific circumstances of the aid project, taking up the alternative offer would mean that the orphanage would not be built. The nature of the alternative job offer varied: It was either objectively attractive (i.e., very lucrative; high objective demands) or not (low objective demands) and either subjectively appealing (i.e., the position one had always dreamed of; high subjective demands) or not (low subjective demands). ${ }^{8}$ Participants were then asked three questions. First, they indicated what they would do in such a situation. Second, they answered the question 'Overall, what is the thing to do?' Third, they indicated what they believed morality demanded them to do.

As reported above, our original interest was to test two hypotheses in the context of the overdemandingness problematic. However, our results also included the interesting finding that increasing consequentialist demands led to a change in some participants' moral assessment of the situation: when demands were high they took the nonconsequentialist action to be the morally right one, whereas when demands were low they claimed it not to be demanded by morality (Bruder and Tanyi, 2014).

To see whether these moral judgments were intuitive, we tested, in line with the new methodology, participants' anticipated emotional reactions to increasing consequentialist demands. In particular, participants were asked about their anticipated emotional reactions were they not to take the consequentialist option. For example, in the Africa scenario described above, we asked participants how much they would expect to experience negative emotions if they chose to take the job and not go to Africa. Participants were 1,001 adults (511 female) with a mean age of 47.6 years and a standard deviation of 18 years. The vast majority of the participants were native German speakers $(n=932)$ with another 66 reporting good/very good German skills and only 3 reporting German language skills of fair or worse. 
We expected that (a) Hypothesis 1: increasing consequentialist demands lead to the anticipation of less negative moral emotions when supposing that one acts against consequentialist demands and that (b) Hypothesis 2: less negative anticipated moral emotions would correspond to increasing dissent with consequentialism.

Hypothesis 1 was indeed confirmed (see Figure 11.1). Higher demands (both objective and subjective) led participants to anticipate less negative moral emotions when acting against consequentialist moral demands. ${ }^{9}$

Hypothesis 2 also found support: In each of the six scenarios, the probability of holding that the consequentialist course of action was not demanded by consequentialism (i.e., dissent with consequentialism) was strongly associated with a lower intensity of self-reported anticipated negative emotions when acting against consequentialism. Spearman correlation coefficients between dissent with consequentialism and emotional intensity in the six scenarios ranged from -0.42 to -0.57 (all significant at $p<0.001)$.

As long as one accepts that emotions are non-inferential, the fact that both hypotheses were confirmed lends credibility to the idea that the moral judgments made by participants were intuitive in the sense of being non-inferential as well.

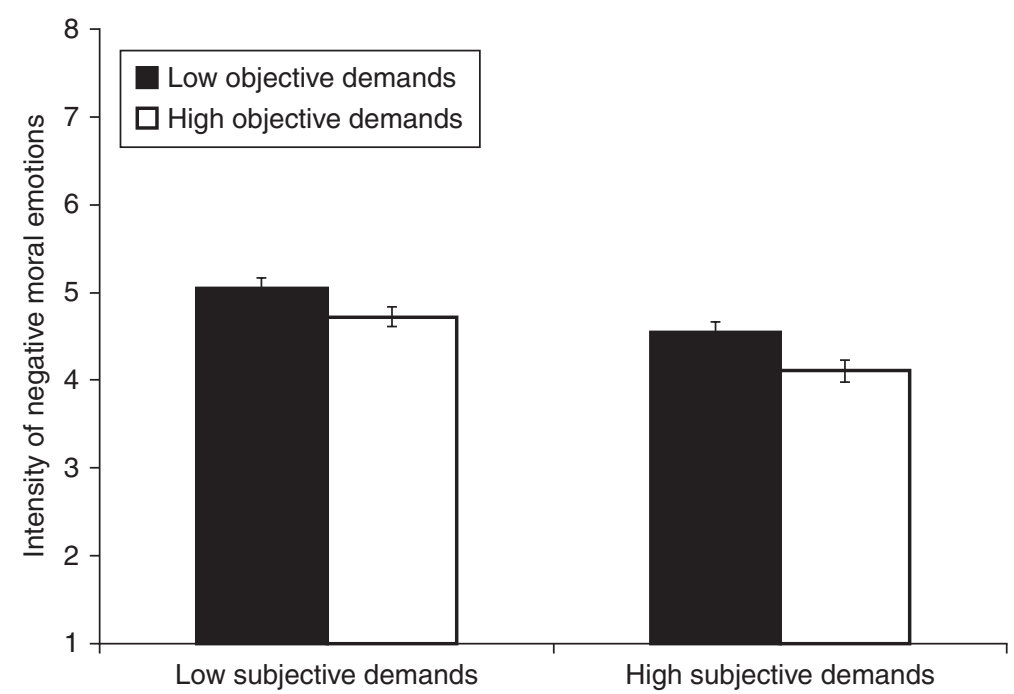

Figure 11.1 Intensity of negative moral emotions under the supposition of acting against consequentialist demands averaged across the six scenarios for each level of objective and subjective demands 


\section{PROOF}

\subsection{Summary}

Examining folk intuitions about philosophical questions lies at the core of experimental philosophy. This requires both a good account of what intuitions are and methods allowing assess to them. In this paper we have proposed to combine philosophical and psychological conceptualizations of intuitions by focusing on three of their features: immediacy, lack of inference, and stability. With this account at hand, we have moved on to develop a methodology that can test all three characteristics without eliminating any of them. In the final part of the paper, we have then proposed implementations of the new methodology as applied to the experimental investigation of the so-called overdemandingness objection to consequentialism. Given constraints of space, our discussion, concerning all these points, was necessarily short and somewhat sketchy, requiring important details to be filled in. Nevertheless, we believe that there is sufficient ground to claim that there are (good) prospects for a new and more adequate methodology in experimental moral philosophy.

\section{Acknowledgments}

We would like to thank audiences in Konstanz, the Hague, Nottingham, Bayreuth, and Lucca, as well as all those who have commented on prior versions of the manuscript. This particularly applies to the editors of the present volume, Christoph Luetge, Hannes Rusch, and Matthias Uhl. The research reported in this paper was funded by several grants from the Zukunftskolleg at the University of Konstanz. It was also supported by a grant to Attila Tanyi from the German Research Foundation (Grant number: TA 820/1-1).

\section{Notes}

1. By speaking of 'moral truth' we are not intending to take sides in the metaethical debate whether there are such truths. As far as we are concerned, what we say in the paper should also be compatible with a minimalist account of truth that most moral anti-realists appear to favor (if they are willing to speak of moral truth at all).

2. We propose these characteristics as necessary and sufficient conditions for a mental state to qualify as an intuition. However, we are open to discussion on this point.

3. We do not, at this point, make a distinction between moral intuitions and intuitions in general, but use the terms interchangeably. When the difference becomes important, we will make a note of that. 


\section{PROOF}

How to Gauge Moral Intuitions? Prospects for a New Methodology

4. See Tangney, Stuewig, and Mashek (2007) for a review on psychological research on moral emotions; for utilitarianism and the moral emotions, see Fehige and Frank (2010).

5. That this is the best version of OD is argued for in Tanyi (2012).

6. In our scenarios participants were asked to imagine themselves in a situation of a choice with a clear consequentialist alternative, such as donating one's inheritance to charity, and a non-consequentialist option, such as keeping the money to buy a new house. The basic situations were then so manipulated that the demand created by choosing the consequentialist option continuously increased until it reached a high demand level. In each version of each scenario, participants were asked three questions: what they would do, what is overall the thing to do, and what morality demands them to do. For more details on this study see the next section.

7. For recent exceptions demonstrating the promise of the methodology see Suter and Hertwig (2011).

8. The distinction between objective and subjective demands is one we introduced for purposes that is not relevant for the presentation in what follows. Briefly, we claim one's choice to be more objectively attractive than an alternative choice if it is reasonable to assume that there is a (near) consensus concerning a quantitative grading of its attractiveness in the sense of 'the more, the better'. With the notion of subjective demandingness, on the other hand, we aim to capture the phenomenon that different people often perceive the very same thing as differently attractive. A good example are monetary rewards: losing a lot of money is more objectively demanding than losing little and therefore constitutes a difference in objective demandingness; losing a certain amount of money, however, can be very demanding of some (e.g., because they are poor), but relatively less demanding of others (e.g., because they are affluent), thereby constituting a difference in subjective demandingness.

9. Objective demands: $F(1,993)=11.17, p=0.001, \eta_{p}^{2}=0.011$; subjective demands: $F(1,993)=23.44, p<0.001, \eta_{\mathrm{p}}^{2}=0.023$.

\section{References}

Aguiar, F., P. Branas-Garza, and L. M. Miller (2008) 'Moral Distance in Dictator Games', Judgment and Decision Making Journal, 3, pp. 344-354.

Alexander, J. and J. M. Weinberg (2007) 'Analytic Epistemology and Experimental Philosophy', Philosophy Compass, 2, pp. 56-80.

Appiah, K. A. (2008) Experiments in Ethics (Cambridge, MA: Harvard University Press).

Banerjee, K., B. Huebner, and M. Hauser (2011) 'Intuitive Moral Judgments Are Robust across Demographic Variation in Gender, Education, Politics, and Religion: A Large-scale Web-based Study', Journal of Cognition and Culture, 10, pp. 253-281.

Bruder, M. and A. Tanyi (2014) 'Consequentialism and Its Demands: A Representative Study', Journal of Value Inquiry, 48 (2), pp. 293-314, a special issue edited by S. Roeser and J. Rickard.

Bruder, M. and A. Tanyi (forthcoming) 'Overdemanding Consequentialism? An Experimental Approach', Utilitas. 
Carter, A. (2009) 'Is Utilitarian Morality Necessarily Too Demanding?', in T. Chappell (ed.) The Problem of Moral Demandingness: New Philosophical Essays (London: Palgrave MacMillan), pp. 163-85.

Cherry, T. L., P. Frykblom, and J. F. Shogren (2002) 'Hardnose the Dictator', American Economic Review, 92, pp. 1218-1221.

D'Arms, J. and D. Jacobson (2000) 'The Moralistic Fallacy: On the "Appropriateness" of Emotions', Philosophy and Phenomenological Research, 61, pp. 65-90.

de Sousa, R. (1987) The Rationality of Emotion (Cambridge, MA: MIT Press).

Döring, S. A. (2003) 'Explaining Action by Emotion', Philosophical Quarterly, 53, pp. 214-230.

Döring, S. A. (2007) 'Seeing What to Do: Affective Perception and Rational Motivation', Dialectica, 61, pp. 363-394.

Epstein, S., R. Pacini, V. Denes-Raj, and H. Heier (1996) 'Individual Differences in Intuitive-experiential and Analytical-rational Thinking Styles', Journal of Personality and Social Psychology, 71, pp. 390-405.

Evans, J. (2008) 'Dual-processing Accounts of Reasoning, Judgment, and Social Cognition', Annual Review of Psychology, 59, pp. 255-278.

Fehige, C. and R. H. Frank (2010) 'Feeling Our Way to the Common Good: Utilitarianism and the Moral Sentiments', The Monist, 93, pp. 141-164.

Gibbard, A. (1990) Wise Choices, Apt Feelings: A Theory of Normative Judgement (Cambridge, MA: Harvard University Press).

Gilbert, D. T. and J. G. Hixon (1991) 'The Trouble of Thinking: Activation and Application of Stereotypic Beliefs', Journal of Personality and Social Psychology, 60, pp. 509-517.

Glöckner, A. and C. Witteman (eds.) (2010) Foundations for Tracing Intuition: Challenges and Methods (New York, NY: Psychology Press).

Goldie, P. (2007) The Emotions: A Philosophical Exploration (Oxford, UK: Oxford University Press).

Goldman, A. I. (2007) 'Philosophical Intuitions: Their Target, Their Source, and Their Epistemic Status', Grazer Philosophische Studien, 74, pp. 1-26.

Greene, J. D., R. B. Sommerville, L. E. Nystrom, J. M. Darley, and J. D. Cohen (2001) 'An fMRI Investigation of Emotional Engagement in Moral Judgment', Science, 293, pp. 2105-2108.

Haidt, J. (2001) 'The Emotional Dog and Its Rational Tail: A Social Intuitionist Approach to Moral Judgment', Psychological Review, 108, pp. 814-834.

Haidt, J. and S. Kesebir (2010) 'Morality', in S. Fiske and D. Gilbert (eds), Handbook of Social Psychology (Hobeken, NJ: Wiley), pp. 797-832.

Hales, S. D. (2000) 'The Problem of Intuition', American Philosophical Quarterly, 37, pp. 135-147.

Hintikka, J. (1999) 'The Emperor's New Intuitions', Journal of Philosophy, 96, pp. 127-147.

Hooker, H. (2009) 'The Demandingness Objection', in T. Chappell (ed.), The Problem of Moral Demandingness: New Philosophical Essays (London: MacMillan), pp. 148-162.

Hookway, C. (2002) 'Emotions and Epistemic Evaluation', in P. Carruthers (ed.), The Cognitive Basis of Science (Cambridge, UK: Cambridge University Press), pp. 251-262.

Horstmann, N., D. Hausmann, and S. Ryf (2010) 'Methods for Inducing Intuitive and Deliberate Processing Modes', in A. Glöckner and C. Witteman 
(eds), Foundations for Tracing Intuition: Challenges and Methods (New York, NY: Psychology Press), pp. 219-237.

Huebner, B. (2011) 'Critiquing Empirical Moral Psychology', Philosophy of the Social Sciences, 41, pp. 50-83.

Kauppinen, A. (2007) 'The Rise and Fall of Experimental Philosophy', Philosophical Explorations, 10, pp. 95-118.

Kohlberg, L. (1984) The Psychology of Moral Development: The Nature and Validity of Moral Stages (San Francisco: Harper \& Row).

Liao, S. M. (2008) 'A Defense of Intuitions', Philosophical Studies, 140, pp. $247-262$.

Little, M. O. (1997) 'Virtue as Knowledge: Objections from the Philosophy of Mind', Noûs, 31, pp. 59-79.

Moors, A. (2009) 'Theories of Emotion Causation: A Review', Cognition \& Emotion, 23, pp. 625-662.

Nagel, J. (2012) 'Intuitions and Experiments: A Defense of the Case Method in Epistemology', Philosophy and Phenomenological Research, 85, pp. 495-527.

Parkinson, B. and A. S. R. Manstead (1993) 'Making Sense of Emotion in Stories and Social Life', Cognition \& Emotion, 7, pp. 295-323.

Peacocke, C. (1992) A Study of Concepts (Cambridge, MA: MIT Press).

Piaget, J. (1999/1932) The Moral Judgment of the Child (Oxon: Routledge).

Podsakoff, P. M., S. B. MacKenzie, J. Y. Lee, and N. P. Podsakoff (2003) 'Common Method Biases in Behavioral Research: A Critical Review of the Literature and Recommended Remedies', Journal of Applied Psychology, 88, pp. 879-903.

Roberts, R. C. (1988) 'What an Emotion Is: A Sketch', Philosophical Review, 97, pp. 183-209.

Roeser, S. (2011) Moral Emotions and Intuitions (Basingstoke, UK: Palgrave Macmillan).

Ryberg, J. (2013) 'Moral Intuitions and the Expertise Defence', Analysis, 73, pp. 3-9.

Schnall, S., J. Haidt, G. L. Clore, and A. H. Jordan (2008) 'Disgust as Embodied Moral Judgment', Personality and Social Psychology Bulletin, 34, pp. 1096-1109.

Sidgwick, H. (1907) The Methods of Ethics, 7th edn (London, UK: Macmillan).

Singer, P. (2005) 'Ethics and Intuitions', Journal of Ethics, 9, pp. 331-352.

Sinnott-Armstrong, W., L. Young, and F. Cushman (2010) 'Moral Intuitions', in J. M. Doris (ed.), The Moral Psychology Handbook (New York, NY: Oxford University Press), pp. 246-272.

Skorupski, J. (2010) The Domain of Reason (Oxford, UK: Oxford University Press).

Slaby, J., A. Stephan, and H. Walter (eds) (2011) Affektive Intentionalität. Beiträge zur welterschließenden Funktion der menschlichen Gefühle (Paderborn, Germany: Mentis).

Solomon, R. (1993) The Passions: Emotions and the Meaning of Life (Indianapolis, IN: Hackett).

Sosa, E. (2006) 'Intuitions and Truth', in P. Greenough and M. P. Lynch (eds), Truth and Realism (Oxford, UK: Clarendon Press), pp. 208-226.

Strack, F., L. L. Martin, and S. Stepper (1988) 'Inhibiting and Facilitating Conditions of the Human Smile: A Nonobtrusive Test of the Facial Feedback Hypothesis', Journal of Personality and Social Psychology, 54, p. 768-777.

Suter, R. S. and R. Hertwig (2011) 'Time and Moral Judgment', Cognition, 119, pp. 454-458. 


\section{PROOF}

174 Martin Bruder and Attila Tanyi

Tangney, J. P., J. Stuewig, and D. J. Mashek (2007) 'Moral Emotions and Moral Behavior', Annual Review of Psychology, 58, pp. 345-372.

Tanyi, A. (2012) 'The Case for Authority', in S. Schleidgen (ed.), Should We Always Act Morally? Essays on Overridingness (Marburg, Germany: Tectum), pp. $159-189$.

Tersman, F. (2008) 'The Reliability of Moral Intuitions: A Challenge from Neuroscience', Australasian Journal of Philosophy, 86, pp. 389-405.

Tracy, J. L. and D. Matsumoto (2008) 'The Spontaneous Expression of Pride and Shame: Evidence for Biologically Innate Nonverbal Displays', Proceedings of the National Academy of Sciences of the United States of America, 105, pp. 11655-11660.

Van Someren, M. W., Y. F. Barnard, and J. A. C. Sandberg (1994) The Think Aloud Method (London, UK: Academic Press). 